\title{
HUBUNGAN TIPE KEPRIBADIAN DAN MOTIVASI KERJA PERAWAT DENGAN MUTU PELAYANAN KEPERAWATAN
}

\author{
Adventy Riang Bevy Gulo ${ }^{1)}$, Henny Syapitri ${ }^{2)}$, Aulia Arman) \\ 1,2,3 Universitas Sari Mutiara Indonesia Medan \\ e-mail korespondensi: adventygulo@yahoo.com
}

\begin{abstract}
ABSTRAK
Mutu pelayanan keperawatan merupakan faktor yang paling penting untuk membentuk kepercayaan pasien kepada layanan keperawatan sehingga tercipta loyalitas dan kepuasan pelanggan. World Health Organization (WHO) menyatakan bahwa 76,68\% perawat di Indonesia memiliki sikap yang ramah terhadap pasien seperti komunikasi efektif, rasa empati perilaku caring. Tujuan penelitian mengetahui hubungan tipe kepribadian dan motivasi kerja perawat dengan mutu pelayanan keperawatan. Desain penelitian analitik korelasi. Pengambilan sampel dalam penelitian ini menggunakan teknik proportionate stratified random sampling dari jumlah total populasi 275 responden dan diperoleh jumlah sampel 73 responden. Analisa data menggunakan analisa univariat dan bivariat dengan uji spearman rank. Hasil penelitian menunjukkan tipe kepribadian introvet perawat mayoritas sebanyak $52.1 \%$, motivasi kerja perawat lemah sebanyak $68.5 \%$, dan mutu pelayanan keperawatan kurang baik sebanyak 58.9\%. Hasil uji statistik spearman rank didapatkan nilai $p$ value sebesar 0,001 artinya ada hubungan antara tipe kepribadian dengan mutu pelayanan dengan nilai $r 0.769$ yang artinya ada hubungan yang sangat kuat antara tipe kepribadian dengan mutu pelayanan. Hasil uji statistik spearman rank didapatkan nilai $p$ value sebesar 0,038 artinya ada hubungan antara motivasi kerja perawat dengan mutu pelayanan keperawatan dengan nilai $r 0.698$ yang artinya ada hubungan yang kuat antara motivasi kerja perawat dengan mutu pelayanan. Kesimpulan penelitian ada hubungan tipe kepribadian dan motivasi kerja dengan mutu pelayanan keperawatan
\end{abstract}

Kata kunci: motivasi kerja; mutu pelayanan; tipe kepribadian

\begin{abstract}
The quality of nursing services is the most important factor to form patient trust in nursing services so as to create customer loyalty and satisfaction. The World Health Organization (WHO) states that $76.68 \%$ of nurses in Indonesia have a friendly attitude towards patients such as effective communication, empathy, caring behavior. The purpose of the study was to determine the relationship between personality type and work motivation of nurses with the quality of nursing services. Correlation analytic research design. Sampling in this study used a proportionate stratified random sampling technique from a total population of 275 respondents and obtained a sample of 73 respondents. Data analysis used univariate and bivariate analysis with Spearman rank test. The results showed that the majority of nurses' introverted personality types were $52.1 \%$, nurses' work motivation was weak as much as $68.5 \%$, and the quality of nursing services was not good as much as 58.9\%. Spearman rank statistical test results obtained a p value of 0.001 meaning that there is a relationship between personality type and service quality with an $r$ value of 0.769 which means there is a very strong relationship between personality type and service quality. Spearman rank statistical test results obtained a p value of 0.038 which means that there is a relationship between the work motivation of nurses and the quality of nursing services with an $r$ value of 0.698 which means that there is a strong relationship between the work motivation of nurses and the quality of service. The conclusion of the study is that there is a relationship between personality type and work motivation with the quality of nursing service.
\end{abstract}

Keywords: personality type, work motivation, service quality 


\section{PENDAHULUAN}

Salah satu organisasi yang menyelenggarakan pelayanan kesehatan perorangan secara paripurna yang menyediakan pelayanan rawat inap, rawat jalan dan gawat darurat adalah rumah sakit. Rumah sakit dituntut meningkatkan kualitas pelayanan kesehatan sehingga mampu bertahan dan berkembang di era jaminan kesehatan nasional saat ini. Kualitas pelayanan rumah sakit sangat didukung oleh sumber daya manusia di dalamnya, salah satunya adalah perawat. Perawat adalah sumber daya manusia yang paling banyak di RS sehigga dituntut untuk memiliki kinerja yang optimal. Salah satu faktor yang turut mempengaruhi kinerja perawat dalam melaksanakan pelayanan keperawatan di rumah sakit adalah tipe kepribadian (Wahjono \& Surabaya, 2015).

Pelayanan keperawatan yang bermutu harus ditopang oleh Sumber Daya Manusia (SDM) dalam hal ini tidak terlepas dari segi keramahtamahan perawat terhadap pasien maupun sesama pekerja, maka seorang perawat dapat dilihat dari segi etika dan tindakan seorang perawat selama proses pelayanan keperawatan melalui tipe kepribadiannya (Grönroos, 2007). Tipe kepribadian perawat sebagai pelaku pelayanan mempunyai pengaruh terhadap pola perilakunya terutama dalam memberikan pelayanan kepada pasien apalagi perawat senantiasa mendampingi pasien 24 jam. Oleh karena itu, rumah sakit cenderung menempatkan perawat sesuai dengan tipe kepribadian tertentu dalam posisi tertentu. Perbedaan kualitas kepribadian perawat ini tentunya akan mempengaruhi mutu pelayanan kesehatan secara keseluruhan. (Soeprodjo et al., 2017)

World Health Organization (WHO) menyatakan bahwa 76,68\% perawat di Indonesia memiliki sikap yang ramah terhadap pasien seperti komunikasi efektif, rasa empati perilaku caring, buktinya banyak perawat yang di minta untuk bekerja diluar negeri termasuk negara Jepang, Arab Saudi, Singapura dan negara negara lain didunia. (Katuuk et al., 2017).

Berdasarkan hasil survei $72,53 \%$ perawat di Indonesia masih banyak yang tidak bekerja secara tim termasuk kolaborasi dalam perawatan pasien dan komunikasi efektif masih kurang baik, sehingga banyak pasien yang kurang puas terhadap pelayanan keperawatan. (Riskesdas, 2018). Data dari Departemen Kesehatan Republik Indonesia pada tahun 2017 68,34\% perawat di sumatera utara penerapan komunikasi efektif masih belum berjalan dengan baik termasuk logat bahasa dan tekanan intonasi dari nada suara yang di terapkan ketika proses keperawatan berlangsung, sehingga banyak pasien di luar sumatera utara yang mengatakan bahwa perawat di Sumatera Utara tidak ramah (Kemenkes RI, 2017).

Berdasarkan data dari sebuah Rumah Sakit di Aceh, diketahui bahwa jumlah perawat selama tahun 2018 adalah sebanyak 275 orang. Hasil wawancara dengan kepala ruang di unit rawat inap diketahui bahwa sebagian perawat yang bekerja kurang sabar dan agak acuh dalam memberi pelayanan bagi pasien dan keluarga. Akibatnya, beberapa pasien yang datang berobat menjadi kecewa dan kurang tertarik melakukan pengobatan selanjutnya. Berdasarkan hasil laporan Instalasi rawat inap jumlah BOR (Bed Occupation of Rate) tidak stabil dimana pada bulan Januari 2016Desember 2018 BOR (Bed Occupation of Rate) adalah 38,68 \% pada tahun 2016, kemudian tahun 2017 terjadi peningkatan 54,23\% 
dan tahun 2018 terjadi penurunan yang signifikan $37,89 \%$.

Berdasarkan hasil wawancara yang dilakukan pada pasien rawat inap sebanyak 10 pasien rawat inap, 8 diantaranya mengatakan bahwa pelayanan keperawatan tidak memuaskan terutama sikap empati dan komunikasi yang diterapkan oleh perawat selama proses perawatan, dan 2 pasien mengatakan agar pelayanan segera diperbaiki. Dalam aspek motivasi kerja, perawat masih terlihat lemah dan semangat kerja kurang sehingga membuat beberapa pasien agak pesimis dengan perkembangan kondisi kesehatan mereka. Akibatnya, terjadi penurunan mutu pelayanan yang diberikan oleh perawat. Oleh karena itu tujuan penelitian ini adalah untuk mengetahui hubungan tipe kepribadian dan motivasi kerja perawat dengan mutu pelayanan keperawatan.

\section{METODE PENELITIAN}

Jenis penelitian ini adalah penelitian kuantitatif dengan pendekatan korelatif dan desain penelitian cross sectional untuk melihat hubungan tipe kepribadian perawat dengan mutu pelayanan keperawatan di sebuah Rumah Sakit di Aceh. Pengambilan sampel dalam penelitian ini menggunakan teknik proportionate stratified random sampling dimana jumlah responden sebanyak 73 orang perawat.

Instrumen yang digunakan berupa kuesioner yang berisi 10 pernyataan untuk tipe kepribadian perawat, 29 pernyataan untuk variabel motivasi dan 25 pernyataan untuk mengukur mutu pelayanan keperawatan rumah sakit. Hasil uji validitas dilakukan terhadap 64 item pertanyaan dengan hasil $\mathrm{r}$ hitung $0,785>\mathrm{r}$ tabel 0,361 , sehingga 64 item pernyataan dari angket dinyatakan valid.

Proses analisa data diawali dengan analisis univariat yaitu menjelaskan karakteristik responden yang disajikan dalam bentuk tabel distribusi frekuensi meliputi jenis kelamin, usia, tingkat pendidikan, dan masa kerja. Dilanjutkan dengan analisis bivariat untuk melihat adanya hubungan tipe kepribadian perawat dengan mutu pelayanan keperawatan di Rumah Sakit. Uji statistik yang digunakan adalah Spearman Rank. Pertimbangan etik penelitian meliputi ethical clearence, izin dan rekomendasi dari Universitas Sari Mutiara Indonesia dan kedua RS, informed consent dari responden, anonymity dan confidentiality. Hasil uji etik dengan nomor 1726/IV/SP/2021 menyatakan bahwa proposal penelitian ini tidak bertentangan dengan nilai dan norma kemanusiaan.

\section{HASIL DAN PEMBAHASAN}

Hasil penelitian menunjukkan bahwa distribusi perawat pelaksana yang menjadi subjek penelitian di sebuah rumah sakit di Aceh, mayoritas berjenis kelamin perempuan $68,5 \%$, mayoritas berusia 21-29 tahun 95,5\%, mayoritas responden berpendidikan D3 Keperawatan 91,8\%, dan mayoritas responden memiliki masa kerja 5-10 tahun $78,1 \%$.

Tabel 1. Distribusi Frekuensi Tipe Kepribadian Perawat di sebuah

Rumah Sakit di Aceh

\begin{tabular}{cccc}
\cline { 3 - 4 } No & $\begin{array}{c}\text { Tipe Kepribadian } \\
\text { Perawat }\end{array}$ & $\boldsymbol{f}$ & $\%$ \\
1 & Introvet & 38 & 52,1 \\
2 & Ekstrovet & 35 & 47,9 \\
& Total & 73 & 100 \\
\hline & Hasil penelitian & \multicolumn{2}{c}{ menunjukkan }
\end{tabular}
bahwa tipe kepribadian perawat pelaksana mayoritas introvet sebanyak 38 orang $(52,1 \%)$ yang artinya perawat sering mengambil keputusan yang diambil didasarkan pada perasaan, pemikiran, dan pengalamannya sendiri. Perawat lebih suka menyendiri, menghabiskan waktu libur dengan sendiri, banyak menjadi pendengar dari pada berbicara meskipun ada masalah yang di selesaikan dan 
malu tampil di depan orang banyak. Individu dengan tipe kepribadian seperti ini biasanya pendiam dan suka menyendiri, merasa tidak butuh orang lain karena merasa kebutuhannya bisa dipenuhi sendiri (Yanti \& Warsito, 2013). Hal ini sejalan dengan penelitian yang dilakukan oleh Effendi et al. (2009) dan (Runtu \& Hamel, 2018) menyatakan bahwa mayoritas perawat memiliki tipe kepribadian introvert.

Hasil penelitian ini juga menunjukkan bahwa terdapat $47.9 \%$ responden memiliki tipe kepribadian ekstrovet yang artinya segala sikap dan keputusan-keputusan yang diambil oleh seorang perawat berdasarkan pada pengalaman pengalaman orang lain dan memiliki sikap ramah, terbuka, aktif dan suka bergaul. Hasil pernyataan perawat di Rumah Sakit, perawat dengan tipe kepribadian ekstrovet sangat senang berkenalan dan berinteraksi dengan orang lain dan tidak suka bekerja sendiri. Hasil penelitian ini sejalan dengan penelitian yang dilakukan oleh Yanti \& Warsito (2013) yang menyatakan bahwa $80,36 \%$ perawat memiliki tipe kepribadian ekstrovet. Hasil penelitian lainnya menyatakan bahwa $78 \%$ perawat memiliki tipe kepribadian ekstrovet. Jadi dapat simpulkan bahwa semakin banyak meningkatnya tipe kepribadian ekstrovet seorang perawat maka, tingkat kepuasan klien yang dirawat semakin meningkat sehingga seorang perawat lebih mudah dalam melakukan tugasnya sebagai seorang perawat (Haryanti \& Hidayat, 2019; Hamel, 2019).

Tabel 2. Distribusi Frekuensi Mutu Pelayanan Keperawatan di sebuah Rumah Sakit di Aceh $(n=73)$

\begin{tabular}{llll}
\hline No & $\begin{array}{c}\text { Mutu Pelayanan } \\
\text { Keperawatan }\end{array}$ & $\boldsymbol{f}$ & $\%$ \\
1 & Baik & 30 & 41,1 \\
2 & Kurang Baik & 43 & 58,9 \\
& Total & 73 & 100 \\
\hline
\end{tabular}

Hasil penelitian menunjukkan bahwa mayoritas menilai mutu pelayanan keperawatan kurang baik yaitu sebanyak 43 orang $(58,9 \%)$. Beberapa faktor yang membuat mutu pelayanan keperawatan kurang baik adalah hasil kinerja yang ditampilkan perawat. Hal ini dapat dilihat dari pelayanan keperawatan dengan kurangnya empati (perhatian) seperti perawat tidak meluangkan waktu untuk berkomunikasi dengan pasien, tidak mengingatkan pasien untuk menyimpan barang berharga, kurangnya memberikan motivasi kepada pasien untuk sembuh, dan responsiveness (daya tanggap) selama memberikan pelayanan keperawatan seperti kurang cepat dan tepat.

Beberapa faktor yang mempengaruhi kinerja perawat dalam pelayanan keperawatan berupa faktor internal yaitu kemampuan dan motivasi, serta faktor eksternal meliputi usia, pengetahuan, tingkat pendidikan, pengalaman kerja, lama kerja dan lingkungan kerja. (Buku Ajar Perilaku Organisasi, n.d.). Hal ini sejalan dengan penelitian yang di lakukan oleh (Effendi et al., 2009), tentang mutu pelayanan keperawatan 55,2\% mutu pelayanan keperawatan ternilai apabila pasien telah menggunakan jasa rumah sakit tersebut dan tingkat kepuasan pasien terhadap pelayanan keperawatan yang telah ia terima maka persepsi pasien terhadap pelayanan keperawatan buruk apabila pelayanan yang di berikan tidak puas mulai dari komunikasi, tindakan keperawatan yang di berikan dan ketepatan seorang perawat dalam memenuhi kebutuhan pelayanan keperawatn baik rawat jalan maupun rawat inap. Jadi dapat di simpulkan bahwa mutu pelayanan keperawatan sangat berperan penting dalam memenuhi tingkat kepuasan pasien selama menerina pelayanan keperawatan.

Tabel 3. Hubungan Tipe Kepribadian dengan Mutu Pelayanan Keerawatan di RSUD H. Sahudin Kutacane

\begin{tabular}{cccccc}
\hline Tipe & \multicolumn{2}{c}{ Mutu Pelayanan } & Jumla & $\boldsymbol{P}$ & \\
Keprib & Kuran & Baik & h & val & $\boldsymbol{r}$ \\
\hline
\end{tabular}




\begin{tabular}{|c|c|c|c|c|c|c|c|c|}
\hline \multirow{2}{*}{ adian } & \multicolumn{6}{|c|}{ g Baik } & \multicolumn{2}{|l|}{ ue } \\
\hline & $\mathrm{n}$ & $\%$ & $\mathrm{~N}$ & $\%$ & $\mathrm{n}$ & $\%$ & & \\
\hline \multirow[t]{2}{*}{ Introvet } & 2 & 39 & 9 & 12 & 3 & 52 & & \\
\hline & 9 & ,7 & & ,4 & 8 &, 1 & & \\
\hline Ekstrov & 1 & 19 & 2 & 28 & 3 & 47 & 0,0 & 0,7 \\
\hline & 4 &, 2 & 1 &, 8 & 5 &, 9 & 01 & 69 \\
\hline \multirow{2}{*}{ Total } & 4 & 58 & 3 & 41 & 7 & 10 & & \\
\hline & 3 & 9 & 0 & 1 & 3 & 0 & & \\
\hline
\end{tabular}

Hasil penelitian menunjukkan bahwa tipe kepribadian perawat mayoritas inntrovet yaitu sebanyak $52,1 \%$ dengan mutu pelayanan keperawatan kurang baik sebanyak $58,9 \%$. Hasil uji statistik spearmen rank didapatkan nilai $p$ value sebesar 0,001 yang artinya ada hubungan yang sangat kuat antara tipe kepribadian dengan Mutu Pelayanan di RSUD H. Sahudin Kutacane dengan nilai $r$ 0.769. Penelitian ini sejalan dengan penelitin (Reza et al., 2018) yang mengatakan ada hubungan tipe kepribadian perawat dalam melaksanakan pelayanan keperawat, dan penelitian sejalan lainnya (Baloch, 2017) mengatakan ada hubungan karakteristik kepribadian dengan penerapan mutu pelayanan keperawatan.

Kepribadian seorang perawat sangat mempengaruhi mutu pelayanan keperawatan baik atau buruknya, karena pada dasarnya dengan tipe kepribadian yang tidak baik maka dalam proses komunikasi, memberikan pelayanan tidak tertata dengan baik (Darmadi, 2008). Hasil penelitian dengan tipe kepribadian perawat yang cenderung introvet sepeti suka menyendiri, merasa tidak butuh orang lain, pendiam dan malu tempil di depan orang banyak maka mutu pelayanan keperawatan menjadi kurang baik, sehingga tingkat kepuasan pasien terhadap mutu pelayanan keperawatan menurun.

\section{KESIMPULAN}

a. Tipe kepribadian Introvet perawat di RSUD H. Sahudin Kutacane di ketahui mayoritas sebanyak 52.1\%.

b. Motivasi kerja lemah perawat di RSUD H. Sahudin Kutacane di ketahui mayoritas sebanyak $68.5 \%$. c. Mutu pelayanan keperawatan di RSUD H. Sahudin Kutacane mayoritas kurang baik sebanyak $58.9 \%$.

d. Diketahui hasil uji statistik spearmen rank didapatkan nilai $p$ value sebesar 0,001 yang artinya ada hubungan yang sangat kuat antara tipe kepribadian dengan Mutu Pelayanan di RSUD H. Sahudin Kutacane dengan nilai $r 0.769$.

e. Diketahui hasil uji statistik spearmen rank didapatkan nilai $p$ value sebesar 0,038 yang artinya ada hubungan yang kuat antara motivasi kerja perawat dengan Mutu Pelayanan keperawatan di RSUD H. Sahudin Kutacane dengan nilai $r$ 0.698 .

\section{SARAN}

a. Bagi Perawat

Disarankan bagi perawat agar tetap profesional dalam bekerja terutama dalam meningkatkan motivasi kerja dalam menjaga mutu pelayanan keperawatan dengan tipe kepribadian ekstrovet sehingga perawat tetap menjaga motivasinya dalam bekerja agar kualitas mutu pelayanan keperawatan tetap terjaga.

b. Bagi Rumah Sakit

Disarankan untuk rumah sakit agar meperhatikan tingkat kepuasan pasien terhadap pelayanan keperawatan dengan memberikan pelatihan karakter kepada perawat pelayanan keperawatan tetap terjaga mutu pelayanannya

c. Bagi peneliti selanjutnya

Bagi peneliti selanjutnya agar dapat mengembangkan penelitian ini dengan memperhatikan faktor lain termasuk tingkat stress, persepsi, tindakan yang mempengaruhi mutu pelayanan keperawatan. Dalam pengumpulan data, lebih baik menggunakan lembar observasi yang bersifat objektif agar hasil yang didapatkan tidak secara subjektif untuk menghindari hasil penelitian yang bias. 


\section{REFERENSI}

Baloch, Q. B. (2017). No 主観的健康感 を中心とした在宅 高齢者におけ る健康関連指標に関する共分 散構造分析Title.

11(1), 92-105.

Buku Ajar Perilaku Organisasi. (n.d.).

Darmadi. (2008). Buku Manajemen Sumber Daya Manusia (Issue July).

Effendi, A. F., Keperawatan, J., Kesehatan, F. I., \& Surakarta, U. M. (2009). Keperawatan Di Rumah Sakit Islam Surakarta.

Grönroos, C. (2007). Service Management and Marketing. In European Journal of Marketing (Vol.

https://doi.org/10.1108/EUM00000 00004874

Haryanti, \& Hidayat. (2019). Hubungan Mekanisme Koping Dengan Stres Kerja Perawat Di Ruang Unit Gawat Darurat Di Rsu Gmim Bethesda Termohon. 7.

Katuuk, M. E., Studi, P., Keperawatanfakultas, I., \& Ratulangi, U. S. (2017). Hubungan Motivasi Kerja Dengan Perilaku Caring Perawat Di Instalasi Gawat Darurat Dan Intensive Care Unit Di Rsu Pancaran Kasih Gmim Manado. Jurnal Keperawatan, 5(2), 1-7.

Reza, R. F., Fitriani, A. R., \& Aries, A. (2018). Hubungan Beban Kerja dan Motivasi Kerja Perawat dengan Kelengkapan Pendokumentasi Asuhan
Keperawatan di Ruang Bedah dan Interna RSUD dr. H. Andi Abdurrahman Noor Kabupaten Tanah Bumbu. Dinamika Kesehatan, 9(2).

Runtu, V. V, \& Hamel, R. (2018). Hubungan Beban Kerja Fisik Dengan Stres Kerja Perawat Diruang Instalasi Rawat Inap Rumah Sakit Umum Gmim Pancaran Kasih Manado. Jurnal Keperawatan, 6(1).

Soeprodjo, R. O. K., Mandagi, C. K. F., Engkeng, S., Kesehatan, F., Universitas, M., \& Ratulangi, S. (2017). Hubungan Antara Jenis Kelamin Dan Motivasi Kerja Dengan Kinerja Perawat Di Rumah Sakit Jiwa Prof. Dr. V. L. Ratumbuysang Provinsi Sulawesi Utara. Kesmas, 6(4).

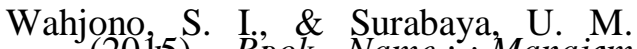

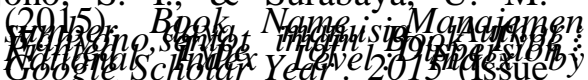
september 2015)

Yanti, R., \& Warsito, B. (2013). Hubungan Karakteristik Perawat, Motivasi, Dan Supervisi Dengan Kualitas Dokumentasi Proses Asuhan Keperawatan. Jurnal Manajemen Keperawatan, 1(2), 111695. 